\title{
The role of noise on the steady state distributions of phytoplankton populations
}

\author{
D Valenti ${ }^{1,2}$, G Denaro ${ }^{3}$, F Conversano ${ }^{4}$, C Brunet ${ }^{4}$, \\ A Bonanno $^{3}$, G Basilone ${ }^{3}$, S Mazzola ${ }^{3}$ and B Spagnolo ${ }^{1,2,5}$ \\ ${ }^{1}$ Dipartimento di Fisica e Chimica, Group of Interdisciplinary Theoretical \\ Physics, Università di Palermo and CNISM, Unità di Palermo, Viale delle \\ Scienze, Edificio 18, 90128 Palermo, Italy \\ ${ }^{2}$ Istituto Nazionale di Fisica Nucleare, Sezione di Catania, Italy \\ ${ }^{3}$ Istituto per l'Ambiente Marino Costiero, CNR, U.O.S. di Capo Granitola, \\ Via del Faro 3, 91020 Campobello di Mazara, Italy \\ ${ }^{4}$ Stazione Zoologica Anton Dohrn, Villa Comunale, 80121 Napoli, Italy \\ ${ }^{5}$ Radiophysics Department, Lobachevsky State University, Nizhniy Novgorod, \\ Russia \\ E-mail: davide.valenti@unipa.it
}

Received 19 October 2015

Accepted for publication 15 December 2015

Published 20 May 2016

Online at stacks.iop.org/JSTAT/2016/054044

doi:10.1088/1742-5468/2016/05/054044

\begin{abstract}
The spatio-temporal behaviour of total chlorophyll concentration is investigated in the middle of the Tyrrhenian Sea by using a stochastic approach. The study is based on a reaction-diffusion-taxis model, which is used to analyse the dynamics of five phytoplankton groups, responsible for about $80 \%$ of the total chlorophyll a inside the euphotic zone of the water column. The analysis is performed by considering: (i) the intraspecific competition of the phytoplanktonic groups for limiting factors, i.e. light intensity and nutrient concentration, (ii) the seasonal changes of environmental variables, and (iii) the random fluctuations of the components of the velocity field and temperature. Specifically, we investigate the effects of external perturbations, both deterministic and random, on the dynamics of phytoplankton populations, by inserting a term of multiplicative noise into the differential equation of the nutrient dynamics. The theoretical results of the phytoplankton abundances obtained by the stochastic model are converted in chlorophyll a concentrations, and compared with the experimental findings. The statistical checks, based on
\end{abstract}


the chi-square test, show that the vertical distributions of total chlorophyll concentration are in a good agreement with the experimental data. Finally, we observe that the high intensity of environmental noise strongly modifies the steady spatial distributions of two phytoplankton groups usually localized in deeper layers, causing algal blooms in surface water.

Keywords: stochastic particle dynamics (theory), hydrodynamic fluctuations, turbulence, stochastic processes (theory)

\section{Contents}

1. Introduction 2

2. The stochastic model 4

$\begin{array}{ll}\text { 3. Results and discussion } & 7\end{array}$

4. Conclusions 16

$\begin{array}{ll}\text { Acknowledgments } & 19\end{array}$

$\begin{array}{ll}\text { References } & 19\end{array}$

\section{Introduction}

The analysis of the spatio-temporal behaviour of phytoplankton abundance in recent decades has assumed a role of fundamental importance in predicting and understanding the effects induced by global climate change over biomass primary production in marine ecosystems [1-4]. In particular, field observations indicated that the reduction of algal production is closely connected to the decrease in the chlorophyll concentration, which depends on the composition and abundance of phytoplankton populations [1, 3-13]. Moreover, it has been shown that the reduced algal production affects biomass production for higher trophic levels, causing a consequent decrease in fish species in the Mediterranean Sea [1-3, 14-16].

In this work, we analyse the complex mechanism responsible for the phytoplankton group displacements along the water column in order to predict the combined effects of the deterministic fluctuations of the physical variables and the random perturbations caused by unpredictable climate change. In particular, we focus our study on the role of the randomly fluctuating components of physical variables, which can cause unexpected algal blooms in the surface layer, characterized in the Tyrrhenian Sea by very low nutrient concentration (oligotrophic water). Indeed, although algal blooms are 
often observed in the surface water of marine ecosystems during the winter season, this phenomenon has not been well investigated yet.

During recent years, it has been shown that seasonal changes in environmental variables can modify the vertical distributions of phytoplankton abundance in such a way to cause a passage from a stability condition with a deep chlorophyll maximum (DCM) to another stability condition with an upper chlorophyll maximum (UCM), and vice-versa [3, 4, 15-19]. In general, this passage can be explained by the nature of marine ecosystems, which are open systems characterized by nonlinear interactions between their parts and external perturbations, both deterministic and random, generated by hydrological and physical variables [4, 16, 17, 19], as often occurs in biological and complex systems [20-33]. Accordingly, in this paper we study the spatio-temporal behaviour of phytoplankton populations by using a stochastic model. This allows the reproduction of the experimental profiles of the chlorophyll a concentration collected during different oceanographic surveys [3, 4, 15, 17-19].

In our model, the photosynthesis process within phytoplankton cells is described by a reaction term, in which are considered the nonlinear interactions between the growth of phytoplankton abundance and the two limiting factors [34-38], i.e. light intensity and nutrient concentration. In particular, the decrease in the light intensity as a function of depth, associated with an opposite gradient of nutrients, guarantees a positive net growth rate within the production layer of each phytoplankton population $[3,16,19]$. In this way, the position and the magnitude of the chlorophyll peak is closely connected with the vertical distribution of the limiting factors [3, 37, 39, 40], which, however, depend on the spatio-temporal behaviour of hydrological and physical variables.

Therefore, it is necessary to take into account the effects of the deterministic perturbations of the environmental variables on the dynamics of phytoplankton populations, according to previous works [3, 4]. Specifically, in our model, the vertical profiles of chlorophyll concentration are reproduced by considering the spatio-temporal behaviour of light intensity and vertical turbulent diffusivity. Moreover, we take into account the seasonal changes of the depth of the thermocline, which is the thin layer of the water column where the absolute value of the temperature gradient assumes the maximum magnitude. We also study the role of random fluctuations of the environmental variable on the phytoplankton dynamics. Regarding this, we recall that the mechanism responsible for the passive movement of phytoplankton groups within the random eddies along the water column is always reproduced by a diffusion term. This term includes the vertical turbulent diffusivity, which is a function of the Richardson number, which also depends on the randomly fluctuating components of the velocity field and temperature [41-43]. Since the measures of these components are not usually available in the analyses of phytoplankton dynamics, several authors have recently estimated the vertical turbulent diffusivity by using measurable average parameters, instead of the randomly fluctuating components of environmental variables [3, 41, 42]. This choice increased the error in the estimation of the vertical turbulent diffusivity and, as a consequence, in the vertical distributions of phytoplankton abundance. Therefore, in order to consider the effects of the random fluctuations of environmental variables on phytoplankton dynamics, we insert a term of multiplicative Gaussian white noise into the differential equation for nutrient dynamics, obtaining a stochastic reaction-diffusion-taxis model. The results obtained are converted into chlorophyll concentration and compared with 
the vertical distributions of total chlorophyll a concentration collected in a marine site in the Tyrrhenian Sea, during four different samplings taken between 24 November 2006 and 9 June 2007. The environmental variables guarantees oligotrophic conditions in the geographical area during the whole year, and phosphorus is the nutrient component playing the role of limiting factor for the growth of the phytoplankton groups $[3,4,15,19,44,45]$.

In more detail, the stochastic model is used to reproduce, under suitable environmental conditions, the spatio-temporal behaviour of five planktonic populations belonging to the smaller size fraction (less than $3 \mu \mathrm{m}$ ), which takes in account, on average, about $80 \%$ of the total chlorophyll a (chl a) and divinyl chlorophyll a (Dvchl a) in the Mediterranean Sea. This fraction consists in picophytoplankton groups belonging to two different domains [46-48], i.e. picoprokaryotes and picoeukaryotes. Specifically, the picoprokaryote domain is composed of two genera of cyanobacteria, i.e. Synechococcus and Prochlorococcus (HL-ecotype and LL-ecotype), while the picoeukaryote domain is mainly represented by Haptophytes and Pelagophytes [49-53].

The dynamics of phytoplankton populations is modelled by considering two different conditions for the noise intensity. As a first step, we solve the equations of the stochastic model by fixing the noise intensity at a constant value during the whole period investigated, according to the procedure followed in previous works [4, 15-18]. Afterwards, we analyse the effects of environmental noise on the phytoplankton dynamics in the presence of a periodical behaviour of the noise intensity, which mimics the seasonal oscillations of the random perturbations. Finally, in both cases studied, we convert the phytoplankton abundance, expressed in cells $/ \mathrm{m}^{3}$, into chl $a$ and Dvchl a concentrations, expressed in $\mu \mathrm{g} / \mathrm{d} m^{3}$, by using the experimental cellular content measured by Morel and the conversion curves obtained by Brunet et al $[50,54]$. The theoretical chlorophyll distributions are therefore compared with the corresponding experimental profiles collected during oceanographic surveys, performing statistical checks based on the $\chi^{2}$ test.

The rest of the paper is organized as follows. In section 2 , a description of the equations of the stochastic reaction-diffusion-taxis model is presented in the two cases studied. In section 3 , the dynamics of the phytoplankton groups obtained by the model is analysed and compared to the experimental findings acquired in four different seasons of the year. Finally, the conclusions are drawn in section 4 .

\section{The stochastic model}

In this section the spatio-temporal behaviour of the five picophytoplankton populations is analysed by using a stochastic reaction-diffusion-taxis model [3, 15-19, 34, 35, 55], consisting of a system of partial differential equations. In particular, the model describes the dynamics of populations along the one-dimensional spatial domain ( $z$-direction) of the Modified Atlantic Water (MAW), i.e. the upper layer of the water column of the Mediterranean Sea (from the surface down to $200 \mathrm{~m}$ ). The domain chosen corresponds approximately to the euphotic zone, namely the layer of the water column where the magnitude of light intensity is enough to guarantee the survival of all phytoplankton groups. 
The spatio-temporal behaviour of the picophytoplankton abundance is modelled considering three processes $[34,35]$ : net growth (reaction term), active movement (taxis term) and passive movement (diffusion term). The reaction term describes the limiting resources, i.e. light intensity and nutrient concentration, influencing the phytoplankton growth rates $[34,36,55-57,59,60]$. The taxis term provides a realistic description of motility skills of the planktonic groups, which tend to be located inside the respective production layers. Finally, the diffusion term reproduces the effect of the turbulence on the vertical profiles of the phytoplankton groups through vertical turbulent diffusivity, which changes as a function of both the time, due to the seasonality, and depth, according to the generalized Fermi function $[3,55]$.

Moreover, the stochastic model takes into account: (i) the nonlinear interactions within the ecosystem due to the intraspecific competition of the phytoplanktonic groups for limiting factors; (ii) the external deterministic perturbations triggered by the seasonal changes of vertical turbulent diffusivity and light intensity; (iii) the randomly fluctuating components of the environmental variables. Therefore, the stochastic fivepopulation $(i=1, \ldots, 5)$ model is defined by the following equations

$$
\begin{aligned}
\frac{\partial b_{i}(z, t)}{\partial t} & =b_{i}(z, t) G_{i}(z, t)+\frac{\partial}{\partial z}\left[D(z, t) \frac{\partial b_{i}(z, t)}{\partial z}\right]-v_{i}\left(\frac{\partial G_{i}(z, t)}{\partial z}\right) \frac{\partial b_{i}(z, t)}{\partial z} \\
\frac{\partial R(z, t)}{\partial t} & =-\sum \frac{b_{i}(z, t)}{Y_{i}} \cdot \min \left(f_{I_{i}}(I), f_{R_{i}}(R)\right)+\frac{\partial}{\partial z}\left[D(z, t) \frac{\partial R(z, t)}{\partial z}\right] \\
& +\sum \varepsilon_{i} m_{i} \frac{b_{i}(z, t)}{Y_{i}}+R(z, t) \xi_{R}(z, t)
\end{aligned}
$$

$I(z, t)=I_{\text {in }}(t) \exp \left\{-\int_{0}^{z}\left[\sum a_{i} \cdot \operatorname{chl} a_{i}(Z, t)+a_{\mathrm{bg}}\right] \mathrm{d} Z\right\}$

where $b_{1}(z, t), b_{2}(z, t), b_{3}(z, t), b_{4}(z, t)$, and $b_{5}(z, t)$ indicate the cell concentrations of the five populations considered, i.e. Synechococcus, Haptophytes, Prochlorococcus HL, Pelagophytes and Prochlorococcus LL, respectively, $R(z, t)$ represents the phosphorus (nutrient) concentration and $I(z, t)$ is the light intensity.

In equation (1), we consider the limiting effect of light intensity and nutrient concentration on the phytoplankton growth rates [34, 36, 56, 57], according to the Monod kinetics [58]. Specifically, we estimate the net phytoplankton growth rates per capita as follows

$$
G_{i}(z, t)=\min \left(f_{R_{i}}(R(z, t)), f_{I_{i}}(I(z, t))\right)-m_{i} .
$$

Here, $m_{i}$ is the specific loss rate of the ith picophytoplankton population [34, 35, 55], while $f_{I_{i}}(I)$ and $f_{R_{i}}(R)$ are obtained by the Michaelis-Menten formulas

$$
\begin{aligned}
& f_{I_{i}}(I)=r_{i} I /\left(I+K_{I_{i}}\right), \\
& f_{R_{i}}(R)=r_{i} R /\left(R+K_{R_{i}}\right),
\end{aligned}
$$


in which $r_{i}$ is the maximum growth rate, $K_{I_{i}}$ and $K_{R_{i}}$ are the half-saturation constants for light intensity and nutrient concentration, respectively, of the $i$ th picophytoplankton group.

In our model, the diffusion terms (see equations (1) and (2)) depend on the vertical turbulent diffusivity, $D(z, t)$, which describes the magnitude of the mixing within the euphotic zone as a function of the depth and time. Specifically, the vertical turbulent diffusivity is characterized by a larger magnitude $D_{U}(t)$ in the upper layer and a smaller magnitude $D_{D}(t)$ in the deeper layers. Since the behaviour of $D_{U}(t)$ and $D_{D}(t)$ is closely connected to seasonal changes, we assume the vertical turbulent diffusivity to be a periodical function which oscillates over a period of one year. Moreover, the gradual transition from the upper mixed layer to deeper layers is given by the following generalized Fermi function [3, 55]

$$
D(z, t)=D_{D}(t)+\frac{D_{U}(t)-D_{D}(t)}{1+\mathrm{e}^{\frac{z-Z_{U}(t)}{w}}},
$$

where $Z_{U}(t)$ is the thickness of the upper mixed layer varying with time, and the parameter $w$ is the width of the transient layer.

In this study, we also consider the active movement of the single planktonic cell by inserting a taxis term in each differential equation for phytoplankton dynamics (see equation (1)). Here, the swimming velocity $v_{i}$ of each group depends on a step function of the gradient of the net phytoplankton growth rate, $\partial G_{i}(z, t) / \partial z[3,34]$. In particular, the swimming velocity is defined as $v_{i}=+v_{i}^{s}$ if $\partial G_{i}(z, t) / \partial z>0, v_{i}=-v_{i}^{s}$ if $\partial G_{i}(z, t) / \partial z<0$, and $v_{i}=0$ if $\partial G_{i}(z, t) / \partial z=0$, where $v_{i}^{s}$ is a constant parameter, whose value (positive) is calculated for each group by using the same formula adopted by Raven [70].

By using equation (2) we reproduce the spatio-temporal dynamics of the phosphorus concentration which, apart the diffusion along the water column, depends on the nutrient uptake necessary to support the phytoplankton metabolism, and the nutrient recycling coming from dead phytoplankton. These two processes are taken into account through the first and last terms, respectively, of equation (2), where $1 / Y_{i}$ is the nutrient content and $\varepsilon_{i}$ is the phosphorus recycling coefficient of the $i$ th picophytoplankton population.

Finally, we use Lambert-Beer's law to reproduce the spatio-temporal behaviour of the light intensity [3, 37, 61, 62]. In particular, this is assumed to decrease exponentially with the depth $z$, due to the shading produced by the chlorophyll molecules present within phytoplankton cells and the marine water turbidity, according to equation (3). Here, $\operatorname{chl} a_{i}(z, t)$ and $a_{i}$ are the chlorophyll concentration and the chl $a$-normalized average absorption coefficient of the ith picophytoplankton population, respectively, $a_{\mathrm{bg}}$ is the background turbidity and $I_{\text {in }}(t)$ is the incident light intensity at the water surface, which oscillates over a period of one year.

The environmental random fluctuations are taken into account in the model by inserting a term of spatially uncorrelated noise into the differential equation for the nutrient dynamics. In particular, we use a source of multiplicative Gaussian noise $\xi_{R}(z, t)$ with intensity $\sigma_{R}$ and statistical properties given by $\left\langle\xi_{R}(z, t)\right\rangle=0$ and $\left\langle\xi_{R}(z, t) \xi_{R}\left(z^{\prime}, t^{\prime}\right)\right\rangle=\sigma_{R} \delta\left(z-z^{\prime}\right) \delta\left(t-t^{\prime}\right)$. More specifically, we investigate the effects of the noise source on the phytoplankton dynamics in two cases. 
Case 1. The noise intensity is kept constant during the whole period investigated $\left(\sigma_{R}(t)=\right.$ const $)$.

Case 2. The noise intensity varies according to the following equation

$$
\sigma_{R}(t)=\sigma_{R}^{\mathrm{av}} \cdot(1.0+\cos \omega t)
$$

where $\sigma_{R}^{\text {av }}$ is the yearly average of the noise intensity fixed along the water column, and $\omega$ is the angular frequency with a period equal to one year. This choice allows us to take into account the periodical behaviour of the noise intensity connected to seasonal changes. In particular, in our analysis the noise intensity takes on the minimum value at the end of the summer (1st September), when the magnitude of the fluctuating components of the velocity field is greatly reduced due to a strong stratification of the water masses and limited wind speed. Conversely, the noise intensity assumes the maximum value at the beginning of March, when the wind stress causes an increase in the fluctuating horizontal velocity components of the marine currents.

Finally, we set the boundary conditions according to those fixed in previous studies $[3,16,19,35,55,60]$. The boundary conditions for the cell concentration of the $i$ th picophytoplankton population have to describe the absence of biomass flux through both the surface layer $(z=0)$ and the deepest layer of the MAW $\left(z=z_{b}\right)$ :

$$
\left.\left[D(z, t) \frac{\partial b_{i}}{\partial z}-v_{i} b_{i}\right]\right|_{z=0}=\left.\left[D(z, t) \frac{\partial b_{i}}{\partial z}-v_{i} b_{i}\right]\right|_{z=z_{b}}=0 .
$$

Moreover, the boundary conditions for the nutrient have to describe the absence of nutrient flux from the water surface $(z=0)$, and fix the phosphorus concentration at the bottom of the MAW $\left(z=z_{b}\right)$ equal to the average value measured $R_{\text {in }}$ :

$$
\left.\frac{\partial R}{\partial z}\right|_{z=0}=0, \quad R\left(z_{b}\right)=R_{\text {in }}
$$

Equations (1)-(10) form the stochastic reaction-diffusion-taxis model used in this work. By solving them, it is possible to obtain the spatio-temporal dynamics of the phytoplankton abundance, which allows for the reproduction of the seasonal changes of total chlorophyll concentration in the Tyrrhenian Sea.

\section{Results and discussion}

In this section we analyse the behaviour of the phytoplankton abundance, numerically solving the stochastic partial differential equations (1)-(10), considered in the Ito sense. The study is performed by using a numerical method based on an explicit finite difference scheme, whose computer implementation consists in a $\mathrm{C}++$ program. Specifically, we integrate the differential equations by implementing a centered-inspace differencing for the diffusion term and an upwind differencing for the taxis term. Moreover, in order to get the stability conditions for both differencing terms [63-68], we set the increment of the spatial variable and the time step at $0.5 \mathrm{~m}$ and $0.05 \mathrm{~h}$, respectively. The values chosen also guarantee the convergence of the finite difference equations [64, 67, 68]. 
In general, the stability conditions depend on the biological and environmental parameters [63-65], whose numerical values are given in table 1 . The biological parameters have been fixed within specific ranges of values, according to the theoretical and experimental results reported in previous works [37, 49, 50, 54, 69-79]. In the present study, we intend to choose the values of the parameters within these ranges in such a way as to guarantee the coexistence of all picophytoplankton populations $[15,19,35$, $55,59]$ along the water column with the environmental conditions observed during the whole period investigated. For this purpose, we perform a preliminary analysis (results here not reported), which indicates that the different values of half-saturation constants, $K_{R_{i}}$ and $K_{I_{i}}$, and nutrient contents, $1 / Y_{i}$, cause significant modifications in the stationary distributions of the phytoplankton cell concentrations. Specifically, we observe that small variations in the half-saturation constants for nutrient concentration, $K_{R_{i}}$, strongly modify the shape of the vertical profiles of phytoplankton abundance. Therefore, the values of the half-saturation constants and nutrient contents for the five phytoplankton groups are chosen in such a way that, not only the coexistence of all the picophytoplankton populations is guaranteed, but also the production layers and the peaks of abundance are placed at depths compatible with the experimental data.

The environmental parameters have been estimated by using the experimental data acquired at the sampling site in the Tyrrhenian Sea in all seasons of the year. Specifically, the spatio-temporal behaviour of the vertical turbulent diffusivity is reproduced according to the methods used by other authors [3, 41, 43, 80-83], using the experimental profiles of density and temperature collected in seven different oceanographic surveys. The behaviour of the incident light intensity at the water surface, $I_{\text {in }}(t)$, is estimated for all days of the year by using the remote sensing data (see the NASA website http://eosweb.larc.nasa.gov/sse/RETScreen/), while the yearly average value of phosphorus concentration at the bottom of the MAW $\left(R_{\text {in }}=0.204 \mathrm{mmol} \mathrm{m}{ }^{-3}\right)$ is fixed on the basis of the analysis performed on the bottle samples (containing sea water collected at the same depth at different periods of the year).

In accordance with previous works [3, 55], as initial conditions, we set for each picophytoplankton group a small cell concentration uniformly distributed along the euphotic zone, while the phosphorus concentration is fixed equal to zero from the water surface to the thermocline, with a linear increase below this point up to the ending of the MAW.

Using values of the biological and environmental parameters in agreement with experimental observations (see table 1), steady seasonal driven oscillations of picophytoplankton abundance are obtained at $t \approx 9 \cdot 10^{4} \mathrm{~h}$. Therefore, we integrate numerically the system (1)-(10) by fixing as a maximum time $t_{\max }=10^{5} \mathrm{~h}$. On this basis, the spatio-temporal dynamics of five phytoplankton populations are reproduced for different values of noise intensity by averaging over 1000 realizations [26, 84].

In both cases studied (see section 2), to compare the theoretical results with the experimental data, the numerical abundance obtained by the stochastic model is converted into chl $a$ and Dvchl a concentrations, fixing the cellular content of Synechococcus equal to $2 \mathrm{fg} c h l a$ cell $^{-1}$, according to the value measured by Morel [54], and using the two curves of mean vertical profile introduced by Brunet et al $[49,50]$ for Prochlorococcus and picoeukaryotes (Haptophytes and Pelagophytes). Moreover, we add to these 
The role of noise on the steady state distributions of phytoplankton populations

Table 1. Parameters used in the stochastic model.

\begin{tabular}{|c|c|c|c|}
\hline Symbol & Interpretation & Units & Value \\
\hline $\begin{array}{l}a_{b g} \\
a_{1} \\
a_{2}=a_{4} \\
a_{3} \\
a_{5} \\
a_{6} \\
r_{1} \\
r_{2} \\
r_{3} \\
r_{4} \\
r_{5} \\
K_{I_{1}} \\
K_{I_{2}} \\
K_{I_{3}} \\
K_{I_{4}} \\
K_{I_{5}} \\
K_{R_{1}} \\
K_{R_{2}} \\
K_{R_{3}}=K_{R_{5}} \\
K_{R_{4}} \\
m_{1} \\
m_{2}=m_{4} \\
m_{3}=m_{5} \\
1 / Y_{1} \\
1 / Y_{2}=1 / Y_{4} \\
1 / Y_{3}=1 / Y_{5} \\
\varepsilon_{1} \\
\varepsilon_{2}=\varepsilon_{4} \\
\varepsilon_{3}=\varepsilon_{5} \\
v_{1}^{s} \\
v_{2}^{s}=v_{4}^{s} \\
v_{3}^{s}=v_{5}^{s} \\
c_{1} \\
c_{2}=c_{4} \\
c_{3}=c_{5} \\
D_{U} \\
D_{D} \\
I_{i n} \\
R_{\text {in }} \\
z_{b} \\
\end{array}$ & 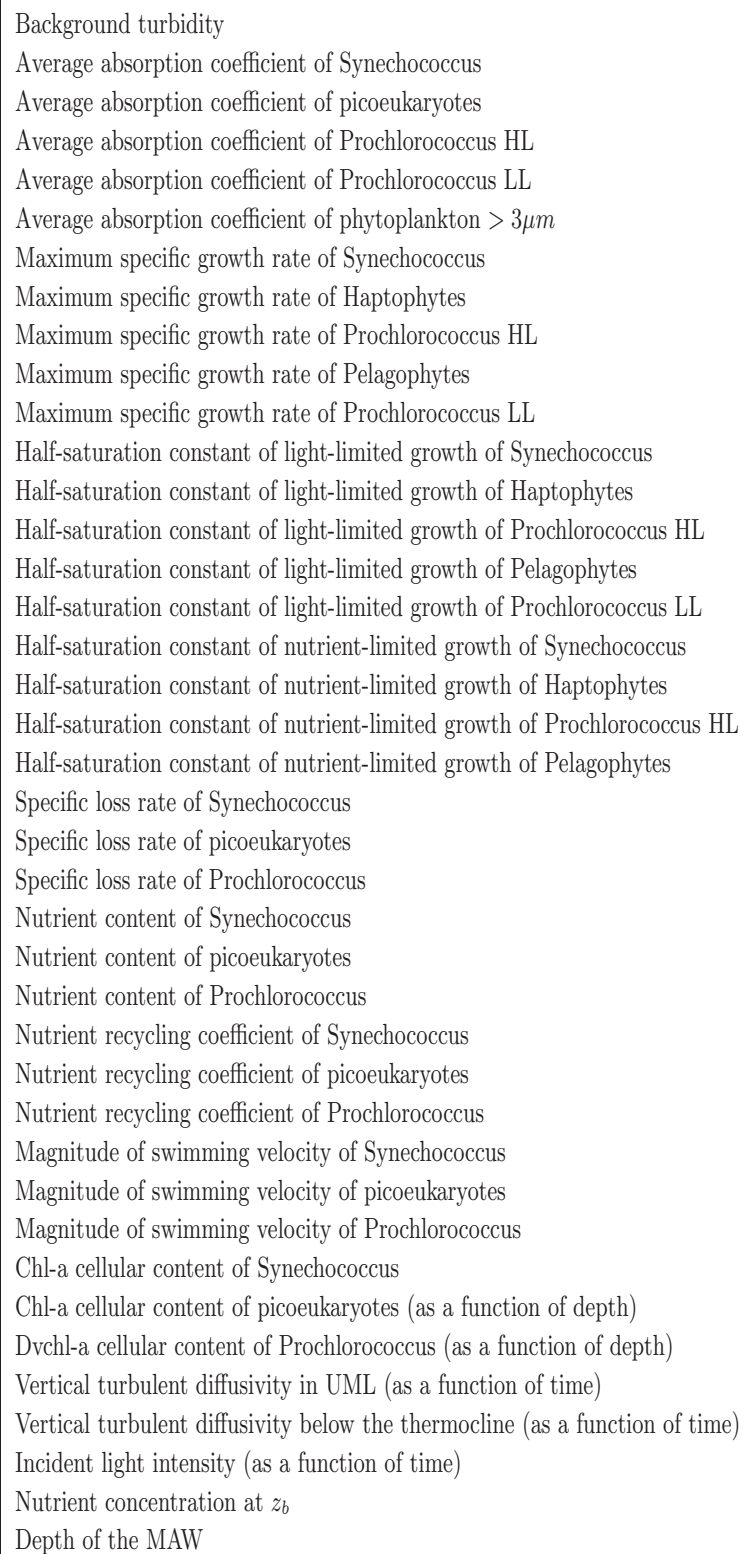 & 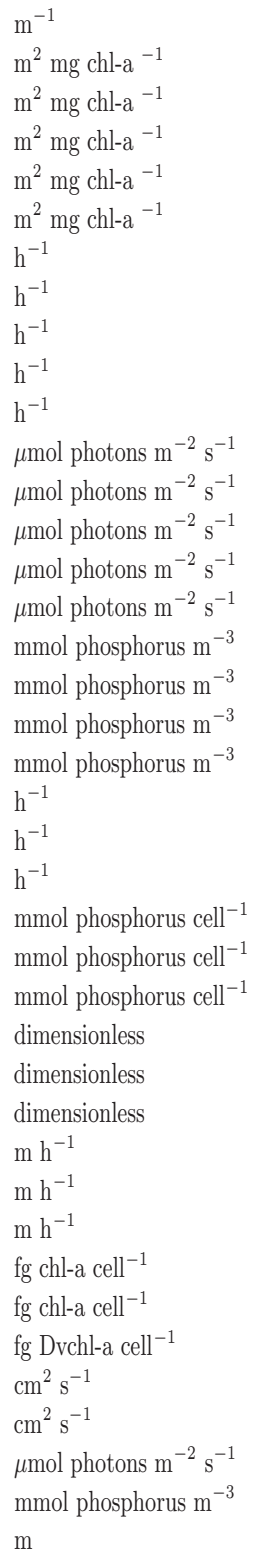 & $\begin{array}{l}0.060 \\
0.025 \\
0.012 \\
0.016 \\
0.027 \\
0.020 \\
0.058 \\
0.079 \\
0.088 \\
0.096 \\
0.031 \\
70.00 \\
90.00 \\
40.00 \\
35.00 \\
6.00 \\
0.00001 \\
0.00004 \\
0.00200 \\
0.01190 \\
0.014 \\
0.010 \\
0.011 \\
2.86 \times 10^{-14} \\
2.00 \times 10^{-12} \\
1.33 \times 10^{-13} \\
0.51 \\
0.52 \\
0.52 \\
0.000088 \\
0.000098 \\
0.000039 \\
2.00 \\
10.00-660.00 \\
0.25-2.20 \\
4.75-28.84 \\
1.25-5.75 \\
314.36-1638.72 \\
0.204 \\
200\end{array}$ \\
\hline
\end{tabular}

converted theoretical results the contribute of chlorophyll concentration, $\Delta b_{(D v) c h l a}$, due to the presence of nano and micro-phytoplankton $(>3 \mu \mathrm{m})$, which is uniformly distributed along the water column and accounts about for $20 \%$ of the total quantity of $c h l a$ and Dvchl $a$. In this way, we obtain the spatio-temporal behaviour of the total chl $a$ and Dvchl a concentration for different values of noise intensity. 
Specifically, the role of the environmental fluctuations is analysed in two different cases: first we include a term of multiplicative noise, in which the noise intensity is kept constant during the whole period investigated; afterwards the noise intensity itself is considered as a seasonal variable, characterized by an oscillating behaviour with a period equal to one year.

Case 1. In figure 1 we show the spatio-temporal behaviour of the $(D v)$ chl a concentration of each picophytoplankton group and the total concentration of $\operatorname{chl} a$ and Dvchl a, obtained for a fixed noise intensity $\left(\sigma_{R}=0.0150\right)$. The numerical results indicate that the production layers of Haptophytes, Prochlorococcus HL and Pelagophytes are localized in intermediate layers of the euphotic zone, causing the presence of a peak of total chlorophyll concentration in correspondence with the experimental DCM during the whole period investigated. Moreover, we observe that the chlorophyll peak for Synechococcus is always localized in shallower layers of the water column, where it reaches the maximum magnitude in the winter season, when high values of vertical turbulent diffusivity determine the nutrient upwelling from the deeper layers. Finally, the map of Prochlorococcus LL shows a reduced chlorophyll concentration localized in the bottom of the MAW during the whole year, in agreement with previous analyses performed in the Tyrrhenian Sea [3, 51, 52].

In order to perform a quantitative comparison between theoretical and experimental distributions, we extract the vertical profiles of the total chl $a$ and Dvchl a concentration from the contour maps obtained by the model for different noise intensities. The results shown in figure 2 indicate that the stochastic model well reproduces the experimental profiles of chlorophyll a concentration during all seasons of the year. Performing the goodness-of-fit test $\chi^{2}$, we note that the stochastic model for a suitable noise intensity $\left(\sigma_{R}=0.0150\right)$ reproduces, in all seasons, the experimental profiles better than the deterministic model $\left(\sigma_{R}=0\right)$. In more detail, we observe that the best value of the reduced chi-square is obtained, depending on the season considered (see table 2), for a different value of noise intensity. Indeed, the best result of the reduced chi-square is obtained in late fall $\left(\tilde{\chi}^{2}=0.00589\right)$ for $\sigma_{R}=0.0010$, in winter $\left(\tilde{\chi}^{2}=0.00130\right)$ for $\sigma_{R}=0.0050$, in early spring $\left(\tilde{\chi}^{2}=0.00664\right)$ for $\sigma_{R}=0.0125$, and in late spring $\left(\tilde{\chi}^{2}=0.00549\right)$ for $\sigma_{R}=0.0200$. These results suggest the constant noise intensity should be replaced with a seasonal driven oscillating function (case 2), in view of improving the agreement between the theoretical and experimental profiles.

To better investigate and understand the effects of random fluctuations on the chlorophyll distributions in all the sampling periods, we analyse the theoretical values of the magnitude, depth and width of the DCM for different noise intensities. The results, shown in figure 3, indicate a nonmonotonic behaviour of the magnitude of DCM as a function of the noise intensity in all seasons of the year. In particular, we observe a peak of total chlorophyll concentration in November, April and June (see panels (a), (g) and ( $\mathrm{j}$ ) in figure 3 ) for $\sigma_{R}=0.0050$. Conversely, in the winter season the magnitude of the DCM takes on a minimum value for $\sigma_{R}=0.0050$ (see panel (d)), while it increases for higher values of noise intensity. Unlike other analyses performed on stochastic models [15, 17-19], in this study we do not observe a connection between the magnitude and width of the DCM. Indeed, the latter reached a maximum value for $\sigma_{R}=0.0050$ in November and February (see panels (c) and (f)), while remaining almost constant for all noise intensities in April and June (see panels (i) and (l)). Finally, in accordance with 
The role of noise on the steady state distributions of phytoplankton populations

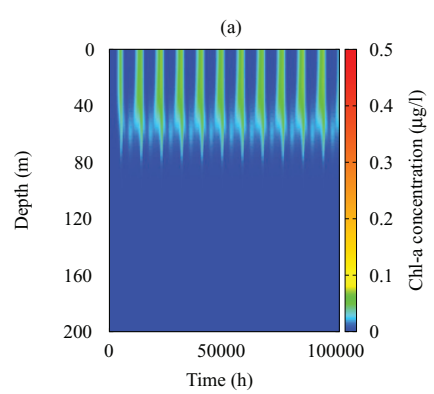

(c)

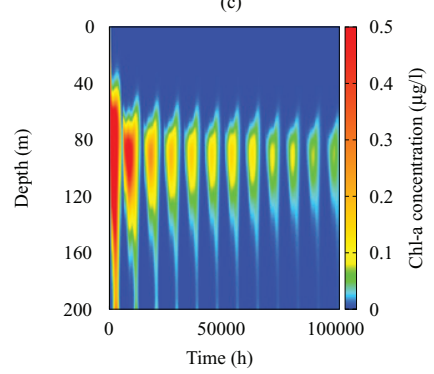

(b)

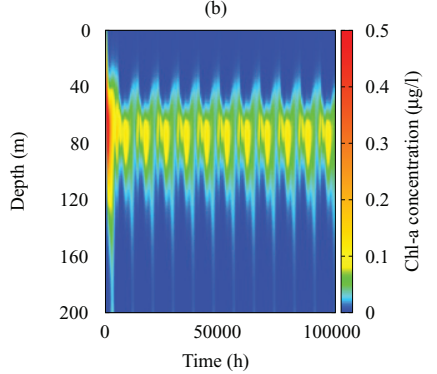

(d)

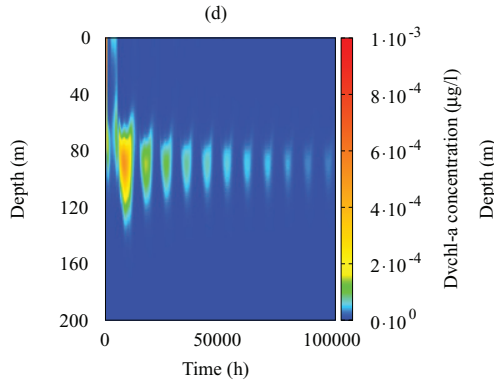

(c)

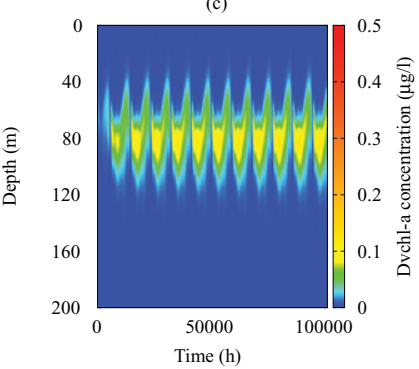

(e)

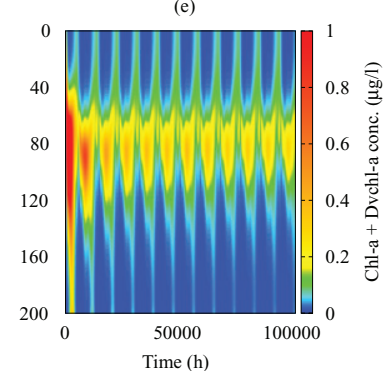

Figure 1. Spatio-temporal behaviour of $\operatorname{chl} a$ and Dvchl $a$ concentrations obtained by the stochastic model in case 1 . The contour maps show the content of chlorophyll for (a) Synechococcus, (b) Haptophytes, (c) Prochlorococcus HL, (d) Pelagophytes, (e) Prochlorococcus LL, and (f) all the phytoplankton groups at the sampling site $\left(39^{\circ} 30^{\prime} .00 \mathrm{~N}, 13^{\circ} 30^{\prime} .00 \mathrm{E}\right)$. The values of the parameters used in the model are those shown in table 1 . The noise intensity is $\sigma_{R}=0.0150$.

previous works $[4,19]$, we also observe that the depth of the DCM remains constant for all values of noise intensity considered and in all the sampling periods (see panels (b), (e), (h) and (k)).

Case 2. According to the procedure followed in case 1, we get the average theoretical distributions during all the sampling periods under the hypothesis that the noise intensity, due to seasonality, follows an oscillating behaviour (see section 2). Thus, the model is modified, assuming that the intensity of the environmental random fluctuations is driven by the same periodical behaviour which characterizes the vertical turbulent diffusivity. As a consequence, we set the periodical function in such a way that the maximum value of the noise intensity is obtained in late winter, while the minimum value is reached at the end of the summer season. The results are shown in figure 4 .

In this case, the $\chi^{2}$ goodness-of-fit test (see table 3 ) exhibits, for $\sigma_{R}^{\text {av }}=0.0150$, very low values of the reduced $\chi^{2}$ in February $\left(\tilde{\chi}^{2}=0.00115\right)$ and in June $\left(\tilde{\chi}^{2}=0.00534\right)$, improving the results previously obtained from the stochastic model in case 1 . Conversely, the $\chi^{2}$ test provides, with respect to case 1 , worse results in the other two sampling periods. In particular, we observe that the best chi-square values are obtained in late fall $\left(\tilde{\chi}^{2}=0.00595\right)$ for $\sigma_{R}=0$ (deterministic analysis) and in early spring $\left(\tilde{\chi}^{2}=0.00672\right)$ for $\sigma_{R}=0.0100$. Considering these results globally, they indicate that the spatio-temporal behaviour of the total chl $a$ and Dvchl a concentration depends on the intensity of the random fluctuations, which appears closely connected to the magnitude of the deterministic fluctuations. Indeed, the best values for the $\chi^{2}$ test are obtained when the noise intensity and the vertical turbulent diffusivity take on simultaneously high (February) or low (June) values. This link between the random 
The role of noise on the steady state distributions of phytoplankton populations
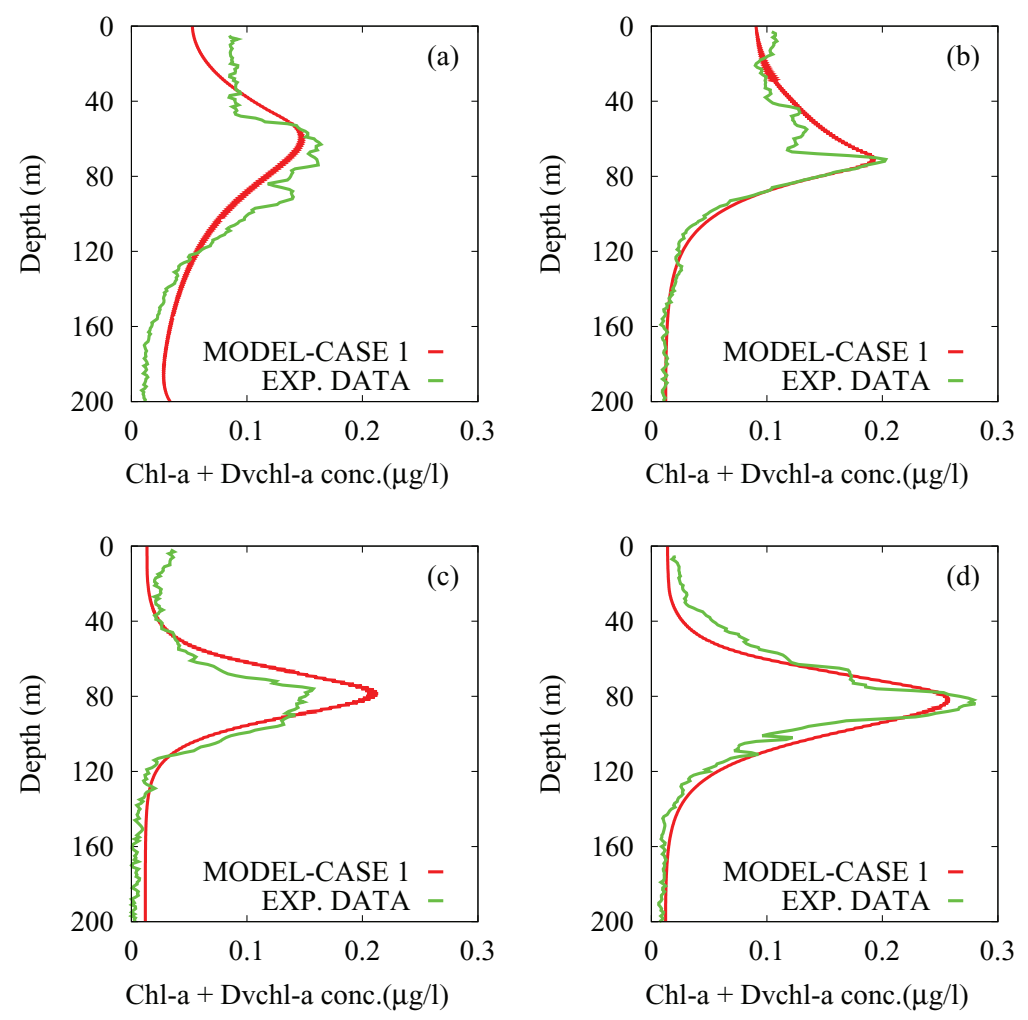

Figure 2. Theoretical distributions (red line) and experimental profiles (green line) of the total chl $a$ and Dvchl $a$ concentration. The numerical results, obtained by the stochastic model (case 1 ) for $\sigma_{R}=0.0150$, are compared with the experimental data collected at the sampling site $\left(39^{\circ} 30^{\prime} .00 \mathrm{~N}, 13^{\circ} 30^{\prime} .00 \mathrm{E}\right)$, during the oceanographic surveys: VECTOR-TM1, 24 November 2006 (panel (a)); VECTOR-TM2, 3 February 2007 (panel (b)); VECTOR-TM3, 22 April 2007 (panel (c)); VECTORTM4, 9 June 2007 (panel (d)).

and deterministic perturbations has been confirmed by other authors [41-43, 85], who proved that the behaviour of the vertical turbulent diffusivity also depends on the fluctuating components of the velocity field and temperature.

Moreover, it is worth stressing the role of environmental noise in the displacement of the peak of the theoretical chlorophyll distributions at the steady state. In particular, for suitable values of noise intensity $\left(\sigma_{R}^{\text {av }} \geqslant 0.0175\right)$ and after a long transient $\left(t \approx 5 \cdot 10^{4} \mathrm{~h}\right)$, we observe a change in the spatio-temporal behaviour of two phytoplankton groups, i.e. Pelagophytes and Prochlorococcus LL, whose production layers are usually localized at the bottom of the MAW, close to the nutrient source (see figure 1). More specifically, the presence of environmental noise affects the vertical distribution of nutrients in the stationary regime, increasing the phosphorus concentration in shallower layers of the water column. In this way, the growth of Pelagophytes and Prochlorococcus LL is also allowed at the top of the MAW, causing an increase in the total chl a and Dvchl a concentration in the water surface (see figure 5). In general, the results of our analysis indicate that the random perturbations of environmental variables could modify the position, shape and magnitude of the chlorophyll maximum during all seasons, causing very marked changes in the biomass primary production, until the equilibrium of the food chain in the marine ecosystem is upset. 
The role of noise on the steady state distributions of phytoplankton populations

Table 2. Results of $\chi^{2}$ and reduced chi-square $\left(\tilde{\chi}^{2}\right)$ goodness-of-fit tests for different values of $\sigma_{R}$.

\begin{tabular}{|l||l|l||l|l||l|l||l|l|}
\hline \multicolumn{1}{|l||}{} & \multicolumn{2}{c||}{ 24 Novemb. 2006 } & \multicolumn{2}{c||}{ 3 February 2007 } & \multicolumn{2}{c||}{ 22 April 2007 } & \multicolumn{2}{c|}{ 9 June 2007 } \\
\hline$\sigma_{R}$ & $\chi^{2}$ & $\tilde{\chi}^{2}$ & $\chi^{2}$ & $\tilde{\chi}^{2}$ & $\chi^{2}$ & $\tilde{\chi}^{2}$ & $\chi^{2}$ & $\tilde{\chi}^{2}$ \\
\hline 0.0000 & 1.167 & 0.00595 & 0.282 & 0.00144 & 1.323 & 0.00675 & 1.312 & 0.00669 \\
\hline 0.0010 & 1.154 & 0.00589 & 0.268 & 0.00137 & 1.314 & 0.00671 & 1.365 & 0.00697 \\
\hline 0.0025 & 1.154 & 0.00589 & 0.272 & 0.00139 & 1.312 & 0.00669 & 1.411 & 0.00720 \\
\hline 0.0050 & 1.267 & 0.00646 & 0.254 & 0.00129 & 1.307 & 0.00667 & 1.776 & 0.00906 \\
\hline 0.0075 & 1.226 & 0.00625 & 0.255 & 0.00130 & 1.305 & 0.00666 & 1.633 & 0.00833 \\
\hline 0.0100 & 1.188 & 0.00606 & 0.256 & 0.00130 & 1.302 & 0.00664 & 1.476 & 0.00753 \\
\hline 0.0125 & 1.164 & 0.00594 & 0.256 & 0.00131 & 1.301 & 0.00664 & 1.324 & 0.00675 \\
\hline 0.0150 & 1.159 & 0.00591 & 0.257 & 0.00131 & 1.306 & 0.00666 & 1.199 & 0.00612 \\
\hline 0.0175 & 1.170 & 0.00600 & 0.258 & 0.00131 & 1.315 & 0.00671 & 1.117 & 0.00570 \\
\hline 0.0200 & 1.195 & 0.00610 & 0.259 & 0.00132 & 1.328 & 0.00678 & 1.075 & 0.00549 \\
\hline
\end{tabular}

Note: The numerical results obtained by the stochastic model in case 1 are compared with the experimental data collected at the sampling site $\left(39^{\circ} 30^{\prime} .00 \mathrm{~N}, 13^{\circ} 30^{\prime} .00 \mathrm{E}\right)$ during the oceanographic surveys: VECTOR-TM1, 24 November 2006; VECTOR-TM2, 3 February 2007; VECTOR-TM3, 22 April 2007; VECTOR-TM4, 9 June 2007. The number of samples (distance of $1 \mathrm{~m}$ ) used for the tests is $n=200$, corresponding to considering the first $200 \mathrm{~m}$ of depth from the surface.

By following the same procedure as in case 1, we study the effects of random fluctuations on the phytoplankton dynamics by analysing the behaviour of the magnitude, depth and width of the chlorophyll maximum as a function of the noise intensity during all the sampling periods (see figure 6).

The numerical results show that, for intermediate values of the average noise intensity $\left(\sigma_{R}^{\text {av }} \leqslant 0.0150\right)$, in November and February the magnitude of the chlorophyll maximum remains almost constant, while a strong increase is observed for higher noise intensities (see panels (a) and (d) in figure 6). Analogously, in April and June, we observe a slight decrease in magnitude for $\sigma_{R}^{\text {av }} \leqslant 0.0175$ followed by a maximum of chlorophyll concentration at $\sigma_{R}^{\mathrm{av}}=0.0200$ (see panels (g) and (j) in figure 6).

In all the sampling periods the depth of the chlorophyll maximum remains almost constant as a function of the average noise intensity for $\sigma_{R}^{\text {av }} \leqslant 0.0175$, while a displacement of the peak of chlorophyll concentration towards the water surface is always observed for higher average noise intensities, except during the winter season (see panels (b), (e), (h) and (k) in figure 6). In accordance with previous results, this behaviour can be explained as an effect of the randomly fluctuating environmental variables, which cause mixing in the shallower layers of the MAW, triggering the upwelling of nutrients when the average noise intensity takes on high values. In these conditions, for suitable values of the environmental parameters, the vertical spatial distributions of the two phytoplankton groups, i.e. Pelagophytes and Prochlorococcus LL, can become unstable, switching from the deep chlorophyll maximum (DCM) to the upper chlorophyll maximum (UCM) configuration $[18,55,60]$. As a consequence, a significant change in the shape of the vertical profile of the total chlorophyll concentration can be induced during the whole year.

Finally, in all seasons we observe nonmonotonic behaviour in the width of the chlorophyll maximum (see panels (c), (f), (i) and (l) in figure 6), which does not appear to be 
The role of noise on the steady state distributions of phytoplankton populations
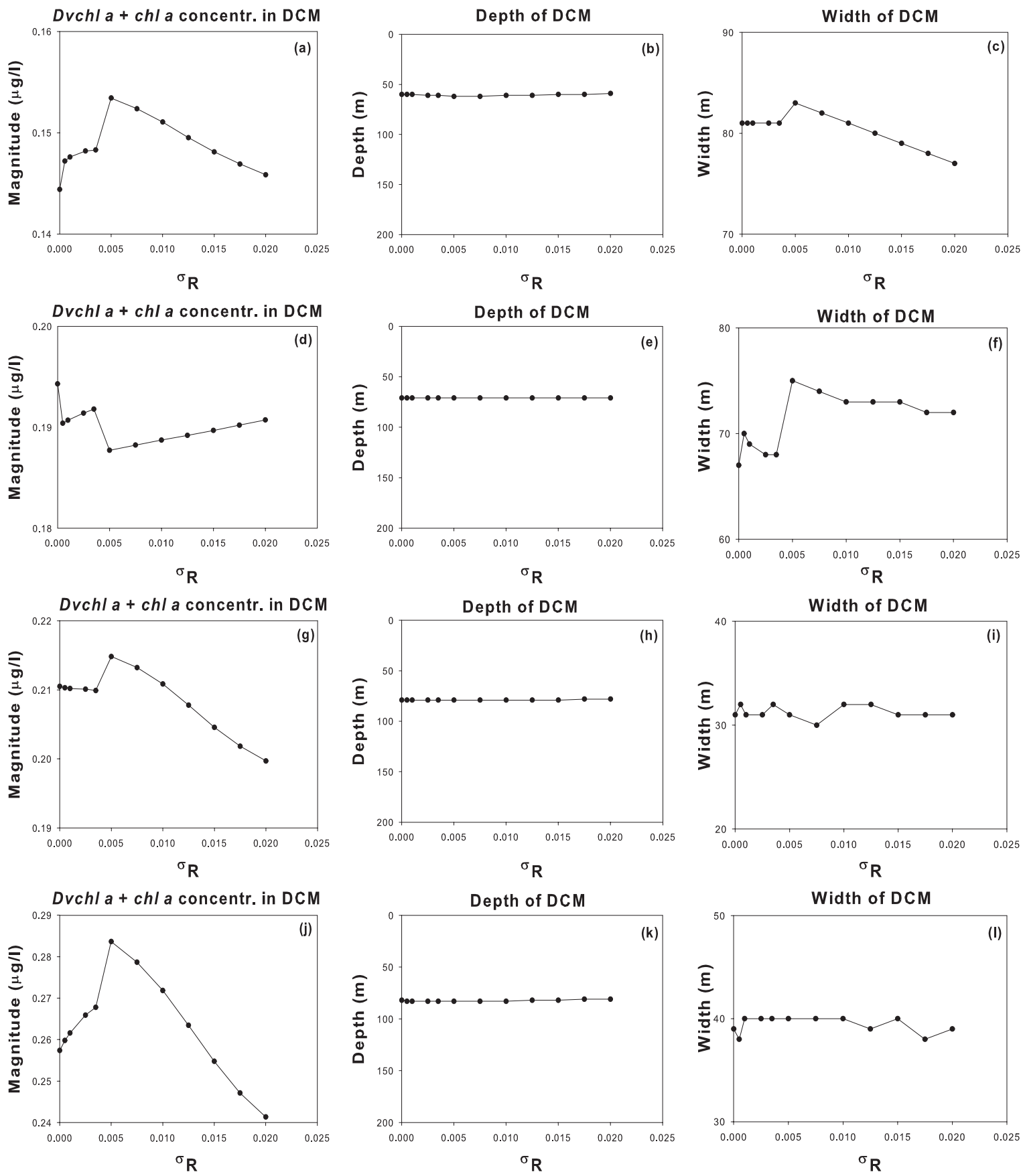

Figure 3. Magnitude, depth, and width of the DCM as a function of $\sigma_{R}$ (case 1 of the stochastic model). The values obtained by the theoretical distributions at the steady state allow us to reproduce the behaviour of the DCM at the site in the Tyrrhenian Sea $\left(39^{\circ} 30^{\prime} .00 \mathrm{~N}, 13^{\circ} 30^{\prime} .00 \mathrm{E}\right)$ during the four different sampling periods: 24 November 2006 (panels (a)-(c)), 3 February 2007 (panels (d)-(f)), 22 April 2007 (panels (g)-(i)), and 9 June 2007 (panels (j)-(l)).

correlated to those of the magnitude and depth. Specifically, in most cases (three seasons over four) the theoretical results, in correspondence with the transition from DCM to UCM configuration, show an increase in the width of the chlorophyll maximum for 
The role of noise on the steady state distributions of phytoplankton populations
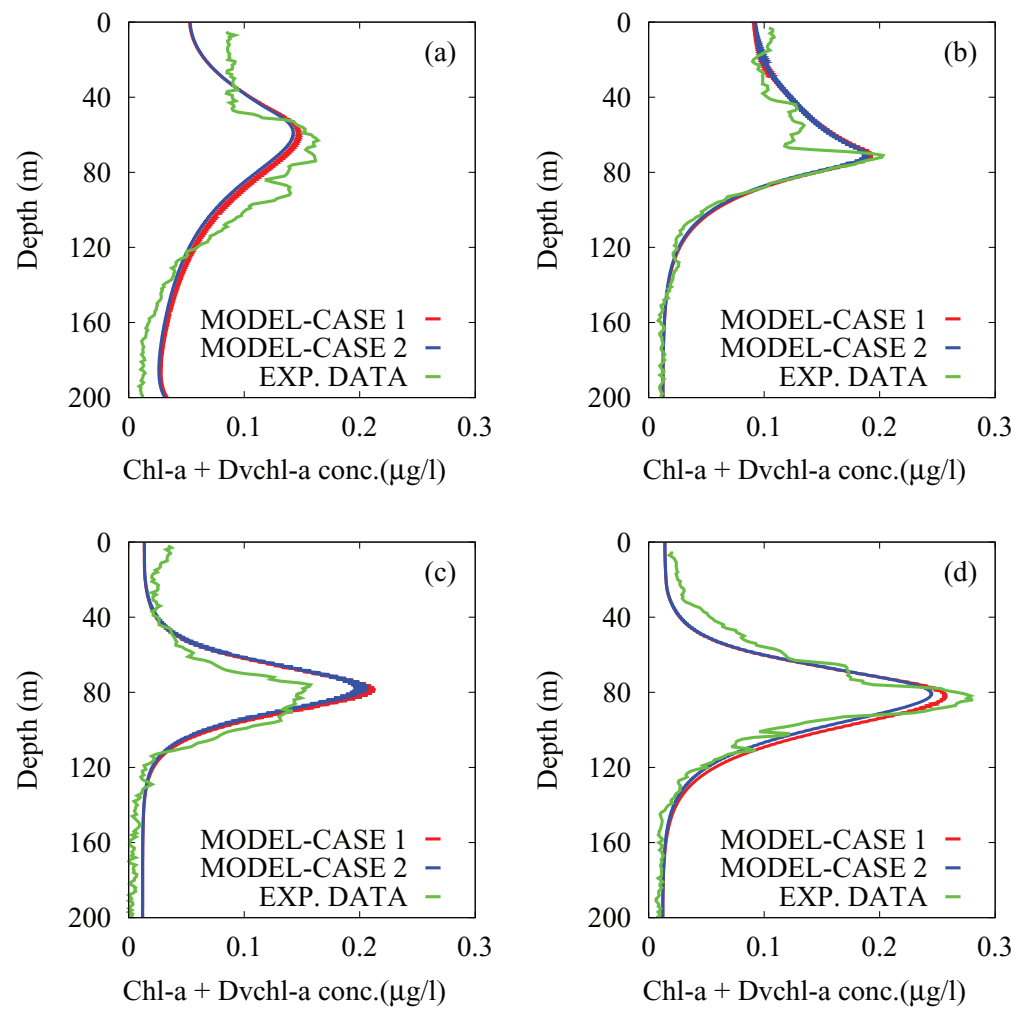

Figure 4. Theoretical distributions for case 1 (red line) and case 2 (blue line), and the experimental profiles (green line) of the total chl $a$ and Dvchl a concentration. The numerical results, obtained by the stochastic model for $\sigma_{R}=0.0150$ (case 1) and $\sigma_{R}^{\text {av }}=0.0150$ (case 2), are compared with the experimental data collected at the sampling site $\left(39^{\circ} 30^{\prime} .00 \mathrm{~N}, 13^{\circ} 30^{\prime} .00 \mathrm{E}\right)$ during the oceanographic surveys: VECTOR-TM1, 24 November 2006 (panel (a)); VECTOR-TM2, 3 February 2007 (panel (b)); VECTOR-TM3, 22 April 2007 (panel (c)); VECTOR-TM4, 9 June 2007 (panel (d)).

Table 3. Results of $\chi^{2}$ and reduced chi-square ( $\left.\tilde{\chi}^{2}\right)$ goodness-of-fit tests for different values of $\sigma_{R}^{\text {av }}$.

\begin{tabular}{|l||l|l||l|l||l|l||l|l|}
\hline \multicolumn{1}{|c||}{} & \multicolumn{2}{c||}{ 24 Novemb. 2006 } & \multicolumn{2}{c||}{ 3 February 2007 } & \multicolumn{2}{c|}{ 22 April 2007 } & \multicolumn{2}{c|}{ 9 June 2007 } \\
\hline$\sigma_{R}^{\text {av }}$ & $\chi^{2}$ & $\tilde{\chi}^{2}$ & $\chi^{2}$ & $\tilde{\chi}^{2}$ & $\chi^{2}$ & $\tilde{\chi}^{2}$ & $\chi^{2}$ & $\tilde{\chi}^{2}$ \\
\hline 0.0000 & 1.167 & 0.00595 & 0.282 & 0.00144 & 1.323 & 0.00675 & 1.312 & 0.00669 \\
\hline 0.0100 & 1.181 & 0.00603 & 0.232 & 0.00118 & 1.316 & 0.00672 & 1.268 & 0.00646 \\
\hline 0.0125 & 1.204 & 0.00614 & 0.228 & 0.00116 & 1.339 & 0.00683 & 1.129 & 0.00576 \\
\hline 0.0150 & 1.245 & 0.00635 & 0.225 & 0.00115 & 1.370 & 0.00699 & 1.047 & 0.00534 \\
\hline 0.0175 & 2.414 & 0.01232 & 8.959 & 0.04571 & 4.140 & 0.02112 & 3.749 & 0.01913 \\
\hline 0.0200 & 6.298 & 0.03213 & 21.931 & 0.11189 & 8.237 & 0.04203 & 8.715 & 0.04446 \\
\hline
\end{tabular}

Note: The numerical results obtained by the stochastic model in case 2 are compared with the experimental data collected in the sampling site $\left(39^{\circ} 30^{\prime} .00 \mathrm{~N}, 13^{\circ} 30^{\prime} .00 \mathrm{E}\right)$ during the oceanographic surveys: VECTOR-TM1, 24 November 2006; VECTOR-TM2, 3 February 2007; VECTOR-TM3, 22 April 2007; VECTOR-TM4, 9 June 2007. The number of samples (distance of $1 \mathrm{~m}$ ) used for the tests is $n=200$, corresponding to considering the first $200 \mathrm{~m}$ of depth from the surface. 
The role of noise on the steady state distributions of phytoplankton populations
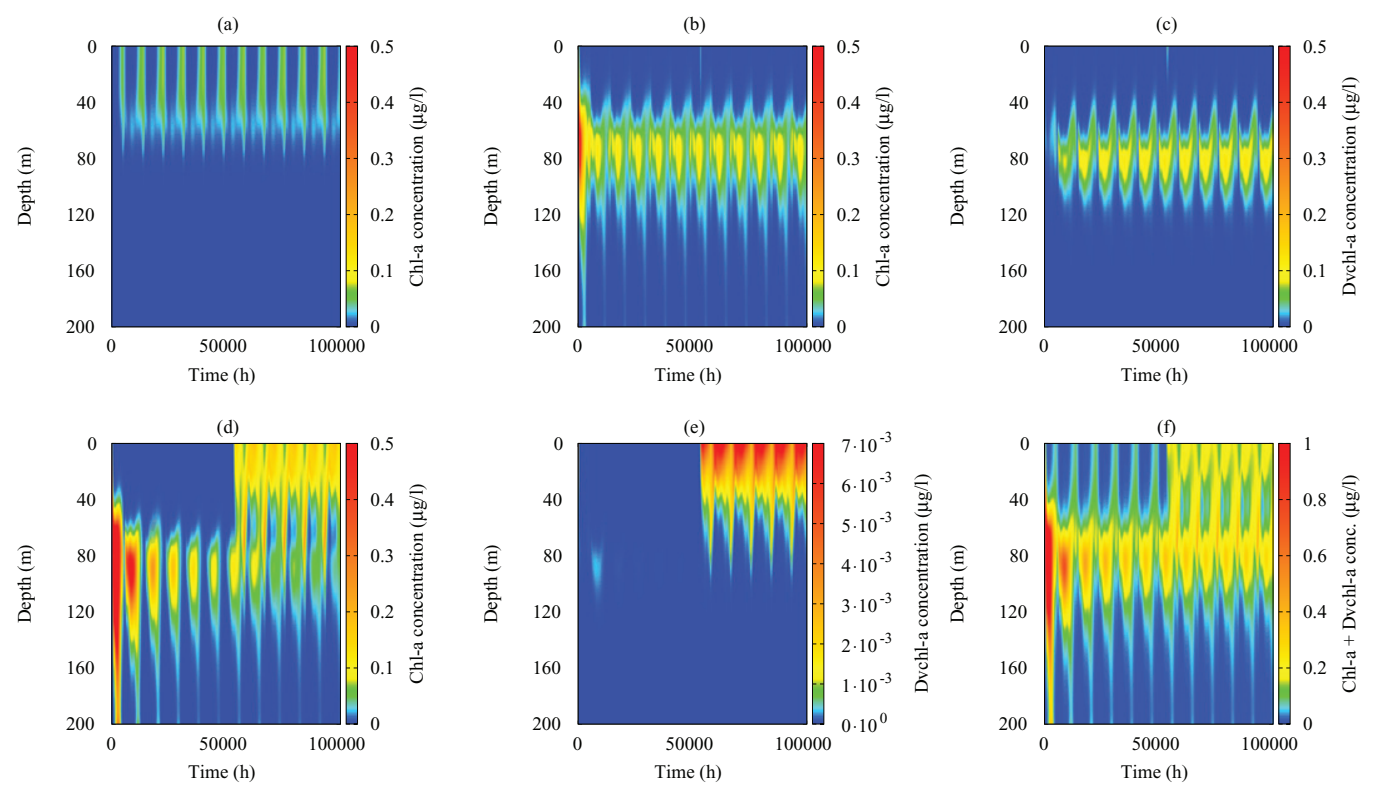

Figure 5. Spatio-temporal behaviour of chl $a$ and Dvchl $a$ concentrations obtained by the stochastic model in case 2 . The contour maps show the content of chlorophyll for (a) Synechococcus, (b) Haptophytes, (c) Prochlorococcus HL, (d) Pelagophytes, (e) Prochlorococcus LL, and (f) all the phytoplankton groups at the sampling site $\left(39^{\circ} 30^{\prime} .00 \mathrm{~N}, 13^{\circ} 30^{\prime} .00 \mathrm{E}\right)$. The values of the parameters used in the model are those shown in table 1 . The noise intensity is $\sigma_{R}^{\text {av }}=0.0175$.

high values of the average noise intensity, with a subsequent strong decrease in the thickness of the upper chlorophyll layer formed.

In conclusion, the analysis performed in this section shows that, in the absence of measured values for randomly fluctuating components of the velocity field and temperature, the stochastic model can reproduce the experimental profiles of the chlorophyll $a$ concentration better than the deterministic ones, in accordance with the results obtained in previous works [4, 15, 17-19]. In particular, the stochastic model provides a more realistic description of the dynamics of the phytoplankton populations because it considers simultaneously both deterministic and random perturbations, which can give rise to two interesting processes: (i) the increase in the total chlorophyll concentration in the upper mixed layer; (ii) the transition from the DCM-UCM configuration. Therefore, this analysis can be extended to other marine ecosystems, to investigate the effects of sudden climate change on phytoplankton populations, which represent the food resource for higher trophic levels [3, 11, 16, 19].

\section{Conclusions}

In recent decades, climate change has caused alterations in the global temperature, hydrological cycles, and flux of nutrients in aquatic ecosystems, which are all essential factors for the growth of the phytoplankton groups [86, 87]. In particular, an increase in nutrient concentration in deeper layers of the euphotic zone, together with a 
The role of noise on the steady state distributions of phytoplankton populations
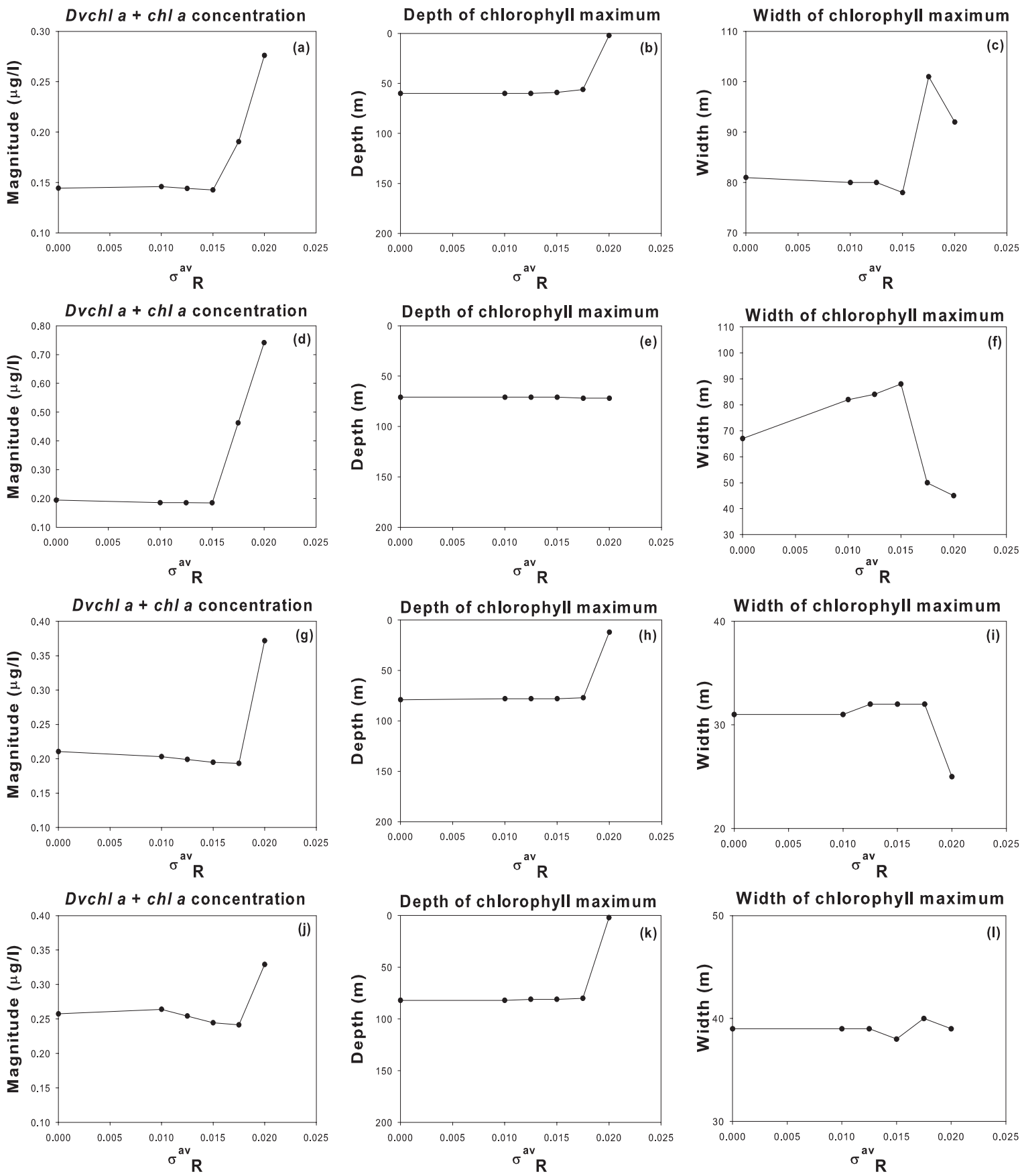

Figure 6. Magnitude, depth, and width of the chlorophyll maximum as a function of $\sigma_{R}^{\text {av }}$ (case 2 of the stochastic model). The values, obtained by the theoretical distributions at the steady state, allow us to reproduce the behaviour of the DCM at the site in the Tyrrhenian Sea $\left(39^{\circ} 30^{\prime} .00 \mathrm{~N}, 13^{\circ} 30^{\prime} .00 \mathrm{E}\right)$ during the four different sampling periods: 24 November 2006 (panels (a)-(c)), 3 February 2007 (panels (d)-(f)), 22 April 2007 (panels (g)-(i)), and 9 June 2007 (panels (j)-(l)).

strengthened stratification of the water column, due to the increase in the surface water temperature, has been observed in the Mediterranean Sea [1, 14, 88, 89]. Here, at the same time, global climate change has also triggered more frequent and severe tropical 
storms, which can support the breaking of the stratification of the water column in an unpredictable way. Since these phenomena could modify the dynamics of the planktonic groups, also causing unexpected algal blooms in oligotrophic waters [55, 60, 90], in this work we performed an innovative analysis of the potential risks for aquatic ecosystems caused by global climate change.

Specifically, we presented a theoretical study based on a stochastic advectiondiffusion-reaction model, in order to reproduce the spatio-temporal behaviour of the total chlorophyll concentration observed at a site in the Tyrrhenian Sea during the sampling period from 24 November 2006 to 9 June 2007. Since the chlorophyll concentration is a marker of the planktonic groups in aquatic ecosystems, the analysis focused on the dynamics of five picophytoplankton populations belonging to two different domains, i.e. picoeukaryotes and picoprokaryotes, which account for about $80 \%$ of the average value of the total chlorophyll $a$ in the Mediterranean Sea.

The spatio-temporal dynamics of the five picoplanktonic groups was studied by solving the stochastic model, taking into account the biological features of each population and the real environmental conditions. Afterwards, in order to compare the theoretical results and experimental profiles of chlorophyll concentration, we converted the theoretical distributions of cell concentration into chl $a$ and Dvchl $a$ concentrations by using the conversion rates obtained in previous works [50, 54]. Finally, we evaluated the agreement between the theoretical chlorophyll distributions and the experimental profiles collected during four different periods of the year, performing a $\chi^{2}$ test.

We recall that the study was carried out considering the external perturbations, both deterministic and random, induced by the mean component and the randomly fluctuating component of the environmental variables, respectively.

Initially, a preliminary deterministic analysis (here not reported) was performed, reproducing the spatio-temporal behaviour of the vertical turbulent diffusivity and light intensity, and analysing their effects on the phytoplankton dynamics in stationary conditions [3]. In this case, the theoretical results indicated the presence of a strong correlation between the vertical profiles of total chl $a$ and Dvchl $a$ concentration and the seasonal deterministic fluctuations of the environmental variables for the whole period investigated. This assumption was confirmed by the quantitative comparison between the theoretical results and experimental findings, performed for all the sampling periods by using the $\chi^{2}$ test.

Afterwards, we modified the deterministic model to show that random fluctuations of environmental variables can significantly influence the vertical profiles of the chlorophyll a concentration in the marine ecosystem investigated.

As a first step, we analysed the results obtained by a stochastic model in which the noise intensity assumes a constant value during the whole period investigated (case 1). Here, we observed that during autumn and winter the upwelling of nutrients is mainly supported by an increase in the vertical turbulent diffusivity in the UML, even if the presence of environmental noise causes a further increase in nutrient concentration in the shallower layers with respect to the deterministic case. This process guarantees a weak increase in the total chl $a$ and Dvchl a concentration in the UML, due to the growth of Synechococcus and Haptophytes [3, 4]. Conversely, during spring and summer, the weak flux of nutrients is mainly supported by the random fluctuations of the 
environmental variables, which do not significantly change the vertical profiles of nutrient concentration.

From a quantitative point of view, the $\chi^{2}$ test showed that the stochastic model (case 1) for suitable noise intensity reproduces the experimental data better than the deterministic model during all the sampling periods.

As a second step, we modified the stochastic model by replacing the constant noise intensity with a seasonal oscillating function (case 2). In particular, we assumed that the magnitude of the noise intensity is strictly correlated to that of the vertical turbulent diffusivity.

From a qualitative point of view, in this case we observed that the presence of random fluctuations for high average noise intensity triggers a strong increase in the nutrient concentration in the upper mixed layer. Here, as a consequence, the best life conditions are guaranteed for all five picophytoplanktonic groups, and the upwelling process generates a strong increase in the total chl $a$ and Dvchl a concentration in the water surface, causing a passage from a stability condition with a deep chlorophyll maximum (DCM) to another stability condition characterized by an upper chlorophyll maximum (UCM) [3, 4, 15-19]. These results confirm the crucial role of the environmental noise for the stability of the population dynamics in aquatic ecosystems.

From a quantitative point of view, in case 2 the $\chi^{2}$ test showed that the stochastic model reproduces the experimental data better than the deterministic one only in three seasons out of four, even if, for an intermediate average noise intensity, the reduced chisquare values obtained in winter and late spring were much better than those obtained in case 1 . This result confirms the connection between deterministic perturbations and random fluctuations.

In conclusion, the model presented in this work seems to be not only an effective tool to describe and reproduce the phytoplankton dynamics considered here, but also a good candidate to predict in general how global climate change is modifying vertical chlorophyll distributions in marine ecosystems.

\section{Acknowledgments}

We acknowledge the financial support from the Ministry of University, Research and Education of the Italian Government, Project PON02_00451_3362121 '(PESCATEC) Sviluppo di una Pesca Siciliana Sostenibile e Competitiva attraverso l'Innovazione Tecnologica', and Project PON02_00451_3361909 '(SHELF-LIFE) - Utilizzo integrato di approcci tecnologici innovativi per migliorare la shelf-life e preservare le proprietà nutrizionali di prodotti agroalimentari'.

\section{References}

[1] Patti B, Guisande C, Bonanno A, Basilone G, Cuttitta A and Mazzola S 2010 Sci. Mar. 74577

[2] Bonanno A et al 2013 Hydrobiologia 701273

[3] Valenti D, Denaro G, Spagnolo B, Conversano F and Brunet C 2015 PLoS One 10 e0115468

[4] Valenti D, Denaro G, Spagnolo B, Mazzola S, Basilone G, Conversano F, Brunet C and Bonanno A 2016 Ecol. Complexity in press

[5] Jennings S, Kaiser M J and Reynolds J D 2001 Marine Fisheries Ecology (Oxford: Blackwell) 
The role of noise on the steady state distributions of phytoplankton populations

[6] Bopp L, Monfray P, Aumont O, Dufresne J L, Treut H L, Madec G, Terray L and Orr J C 2001 Global. Biogeochem. Cy. 1581

[7] Cuttitta A, Carini V, Patti B, Bonanno A, Basilone G, Mazzola S, García Lafuente J and García A 2003 Hydrobiologia 503117

[8] Sarmiento J L et al 2004 Global. Biogeochem. Cy. 18 GB3003

[9] Schmittner A 2005 Nature 434628

[10] Weston K, Fernand L, Mills D K, Delahunty R and Brown J 2005 J. Plankton Res. 27909

[11] Kiørboe T 2008 A Mechanistic Approach to Plankton Ecology (Princeton, NJ: Princeton University Press)

[12] Karsenti E et al 2011 PLoS Biol. 9 e1001177

[13] Melbourne-Thomas J, Constable A, Wotherspoon S and Raymond B 2013 PLoS One 8 e55093

[14] Basilone G, Bonanno A, Patti B, Mazzola S, Barra M, Cuttitta A and McBride R 2013 Fish. Oceanogr. 22309

[15] Denaro G, Valenti D, Spagnolo B, Basilone G, Mazzola S, Zgozi S, Aronica S and Bonanno A 2013 PLoS One 8 e66765

[16] Denaro G 2014 Stochastic models for phytoplankton dynamics in marine ecosystem PhD Thesis, Università di Palermo, Italy, unpublished

[17] Valenti D, Denaro G, La Cognata A, Spagnolo B, Bonanno A, Mazzola S, Zgozi S and Aronica S 2012 Acta Phys. Pol. B 431227

[18] Denaro G, Valenti D, La Cognata A, Spagnolo B, Bonanno A, Basilone G, Mazzola S, Zgozi S, Aronica S and Brunet C 2013 Ecol. Complexity 1321

[19] Denaro G, Valenti D, Spagnolo B, Bonanno A, Basilone G, Mazzola S, Zgozi S and Aronica S 2013 Acta Phys. Pol. B 44977

[20] Grenfell B T, Wilson K, Finkenstädt B F, Coulson T N, Murray S, Albon S D, Pemberton J M, CluttonBrock T H and Crawley M J 1998 Nature 394674

[21] Zimmer C 1999 Science 28483

[22] Bjørnstad O N and Grenfell B T 2001 Science 293638

[23] Spagnolo B, Cirone M, Barbera A L and de Pasquale F 2002 J. Phys.: Condens. Matter 142247

[24] Spagnolo B and La Barbera A 2002 Physica A 315114

[25] Spagnolo B, Fiasconaro A and Valenti D 2003 Fluct. Noise Lett. 3 L177

[26] Spagnolo B, Valenti D and Fiasconaro A 2004 Math. Biosci. Eng. 1185

[27] Valenti D, Fiasconaro A and Spagnolo B 2004 Acta Phys. Pol. B 351481

[28] Caruso A, Gargano M E, Valenti D, Fiasconaro A and Spagnolo B 2005 Fluct. Noise Lett. 5 L349

[29] Goryachev A, Toh D J, Wee K B, Lee T, Zhang H B and Zhang L H 2005 PLoS Comput. Biol. 1 e37

[30] Fiasconaro A, Valenti D and Spagnolo B 2006 Eur. Phys. J. B 50189

[31] Valenti D, Schimansky-Geier L, Sailer X and Spagnolo B 2006 Eur. Phys. J. B 50199

[32] Maye A, Hsieh C H, Sugihara G and Brembs B 2007 PLoS One 2 e443

[33] La Cognata A, Valenti D, Dubkov A A and Spagnolo B 2010 Phys. Rev. E 82011121

[34] Klausmeier C A and Litchman E 2001 Limnol. Oceanogr. 461998

[35] Huisman J, Pam Thi N N, Karl D M and Sommeijer B 2006 Nature 439322

[36] Klausmeier C A, Litchman E and Levin S A 2007 J. Theor. Biol. 246278

[37] Hickman A, Dutkiewicz S, Williams R and Follows M 2010 Mar. Ecol. Prog. Ser. 4061

[38] Beversdorf L, Miller T and McMahon K 2013 PLoS One 8 e56103

[39] Norberg J 2004 Limnol. Oceanogr. 491269

[40] Yeo S K, Huggett M, Eiler A and Rappè M 2013 PLoS One 8 e56207

[41] Denman K L and Gargett A E 1983 Limnol. Oceanogr. 28801

[42] Peters H, Gregg M C and Toole J M 1988 J. Geophys. Res. 931199

[43] Massel S R 1999 Fluid Mechanics for Marine Ecologists (Berlin: Springer)

[44] Thingstad T F and Rassoulzadegan F 1995 Mar. Ecol. Prog. Ser. 117299

[45] Ribera d'Alcalà M, Civitarese G, Conversano F and Lavezza R 2003 J. Geophys. Res. 1088106

[46] Olson R J, Zettler E R and DuRand M D 1993 Phytoplankton analysis using flow cytometry Handbook of Methods in Aquatic Microbial Ecology (Boca Raton, FL: Lewis Publishers) pp 175-86

[47] Casotti R, Landolfi A, Brunet C, D’Ortenzio F, Mangoni O and Ribera d'Alcalà M 2003 J. Geophys. Res. 1088116

[48] Brunet C, Casotti R and Vantrepotte V 2008 J. Plankton Res. 30645

[49] Brunet C, Casotti R, Vantrepotte V, Corato F and Conversano F 2006 Aquat. Microb. Ecol. 44127

[50] Brunet C, Casotti R, Vantrepotte V and Conversano F 2007 Mar. Ecol. Prog. Ser. 34615

[51] Garczarek L et al 2007 FEMS Microbiol. Ecol. 60189

[52] Mella-Flores D et al 2011 Biogeosciences 82785 
The role of noise on the steady state distributions of phytoplankton populations

[53] La Ferla R, Maimone G, Azzaro M, Conversano F, Brunet C, Cabral A S and Paranhos R 2012 Helgol. Mar. Res. 66635

[54] Morel A 1997 Limnol. Oceanogr. 421746

[55] Ryabov A B, Rudolf L and Blasius B 2010 J. Theor. Biol. 263120

[56] Mei Z P, Finkel Z V and Irwin A J 2009 J. Theor. Biol. 259582

[57] Bougaran G, Bernard O and Sciandra A 2010 J. Theor. Biol. 265443

[58] Turpin D H 1988 Growth and Reproductive Strategies of Freshwater Phytoplankton (Cambridge: Cambridge University Press)

[59] Ryabov A and Blasius B 2011 Ecol. Lett. 14220

[60] Ryabov A 2012 Theor. Ecol. 5373

[61] Shigesada N and Okubo A 1981 J. Math. Biol. 12311

[62] Kirk J T O 1994 Light and Photosynthesis in Aquatic Ecosystems 2nd edn (Cambridge: Cambridge University Press)

[63] Roache P J 1976 Computational Fluid Dynamics (Albuquerque, NM: Hermosa Publishers)

[64] Roache P J 1998 Fundamentals of Computational Fluid Dynamics (Albuquerque, NM: Hermosa Publishers)

[65] Tveito A and Winther R 1998 Introduction to Partial Differential Equations: a Computational Approach (Berlin: Springer)

[66] Veldman A E P 2001 Computational Fluid Dynamics (Lecture Notes) (The Netherlands: University of Groningen)

[67] Hundsdorfer W and Verwer J G 2003 Numerical Solution of Time-Dependent Advection-Diffusion-Reaction Equations (Springer Series in Computational Mathematics) (Berlin: Springer)

[68] Pam Thi N N, Huisman J and Sommeijer B P 2005 J. Comput. Appl. Math. 17457

[69] Raven J A, Finkel Z V and Irwin A J 2005 Vie et Milieu 55209

[70] Raven J A 1998 Funct. Ecol. 12503

[71] Dimier C, Brunet C, Geider R and Raven J 2009 Limnol. Oceanogr. 54823

[72] Veldhuis M J W, Timmermans K R, Croot P and Van Der Wagt B 2005 J. Sea Res. 537

[73] Thingstad T F and Sakshaugh E 1990 Mar. Ecol. Prog. Ser. 63261

[74] Quevedo M and Anadón R 2001 Mar. Ecol. Prog. Ser. 22120

[75] Moore L R, Goericke R and Chisholm S W 1995 Mar. Ecol. Prog. Ser. 116259

[76] Bertilsson S, Berglund O, Karl D M and Chisholm S W 2003 Limnol. Oceanogr. 481721

[77] Timmermans K R, van der Wagt B, Veldhuis M J W, Maatman A and de Baar H J W 2005 J. Sea Res. 53109

[78] Rippka R, Coursin T, Hess W, Lichtle C, Scanlan D J, Palinska K A, Iteman I, Partensky F, Houmard J and Herdman M 2000 Int. J. Syst. Evol. Microbiol. 501833

[79] Brunet C, Casotti R, Aronne B and Vantrepotte V 2003 J. Plankton Res. 251413

[80] Oakey N S and Elliott J A 1982 J. Phys. Oceanogr. 12171

[81] Nishimura H and Nakamura Y 1987 Cont. Shelf Res. 71245

[82] Nakamura Y and Hayakawa N 1991 Modelling of thermal stratification in lakes and coastal seas Hydrology of Natural and Manmade Lakes vol 206 (Oxfordshire: International Association of Hydrological Sciences) p 227

[83] Justić D, Rabalais N N and Turner R E 2002 Ecol. Model. 15233

[84] Giuffrida A, Valenti D, Ziino G, Spagnolo B and Panebianco A 2009 Eur. Food Res. Technol. 228767

[85] Mellor G and Yamada T 1982 Rev. Geophys. Space Phys. 20851

[86] Galloway J N and Cowling E B 2002 Ambio 3164

[87] Rabalais N N, Turner R E, Díaz R J and Justić D 2009 ICES J. Mar. Sci. 661528

[88] Bonanno A et al 2014 Ocean Sci. 10759

[89] Rinaldi E, Buongiorno Nardelli B, Volpe G and Santoleri R 2014 Cont. Shelf Res. 7761

[90] Ryabov A B and Blausius B 2008 Math. Model. Nat. Phenom. 342 